Document downloaded from:

http://hdl.handle.net/10251/132416

This paper must be cited as:

Giraldo-Valderrama, JS.; Payri, R.; Marti-Aldaravi, P.; Montiel-Prieto, T. (2018). Effect of high injection pressures and ambient gas properties over the macroscopic characteristics of the diesel spray on multi-hole nozzles. Atomization and Sprays. 28(12):1145-1160. https://doi.org/10.1615/AtomizSpr.2019029651

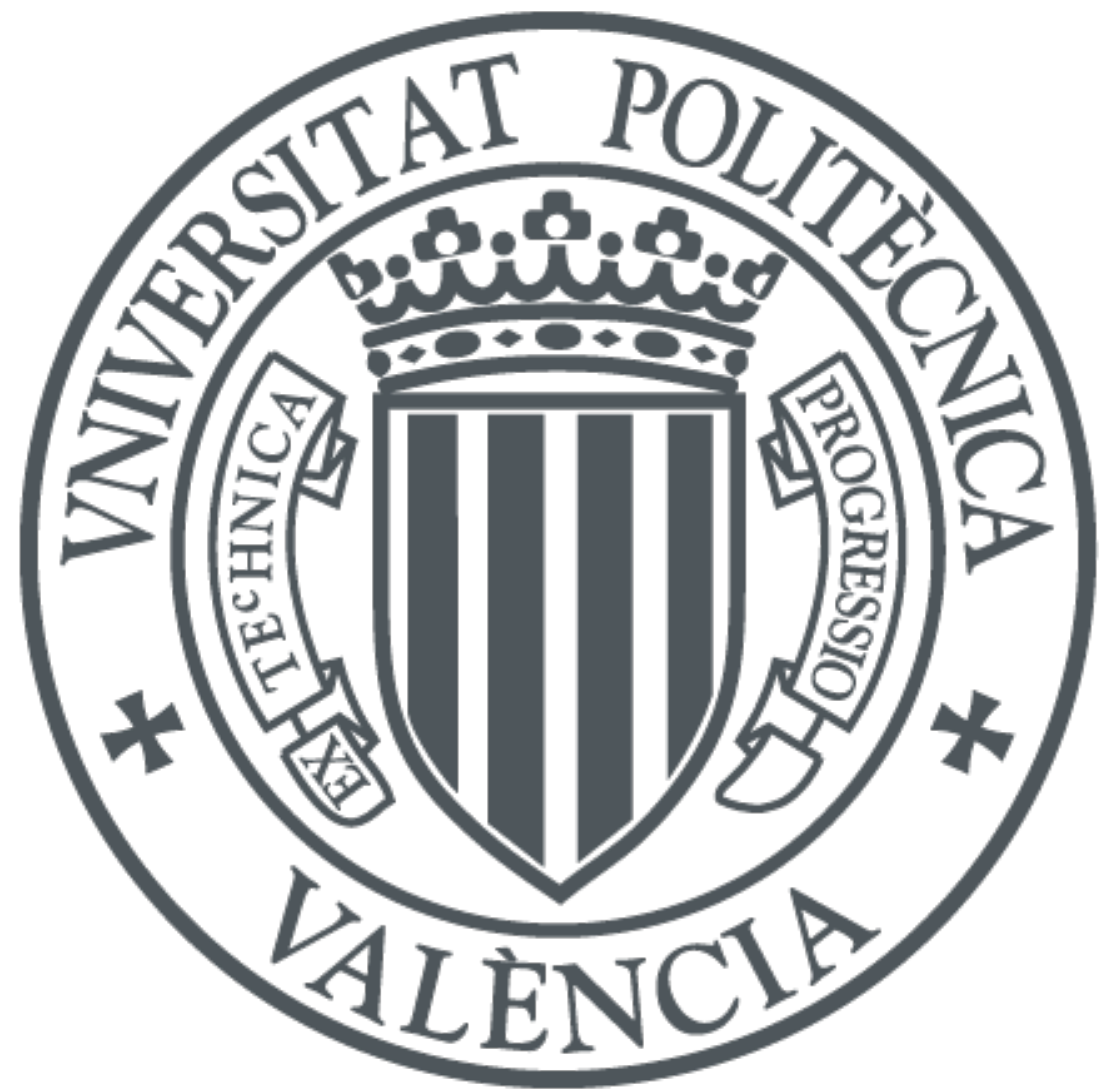

The final publication is available at

https://doi.org/10.1615/AtomizSpr.2019029651

Copyright Begell House Inc.

Additional Information 
Published as: Atomization and Sprays, 2018, Vol 28(12), pp. 1145-1160. DOI: 10.1615/AtomizSpr.2019029651.

\title{
Effect of high injection pressures and ambient gas properties over the macroscopic characteristics of the diesel spray on multi-hole nozzles
}

\author{
Jhoan S. Giraldo ${ }^{1, *}$, Raúl Payri² ${ }^{2}$ Pedro Martí-Aldaraví2 ${ }^{2}$ Tomas Montiel ${ }^{2}$ \\ ${ }^{1}$ FEV France, 11 Rue Denis Papin, 78190 Trappes, France. \\ ${ }^{2}$ CMT - Motores Térmicos, Universitat Politècnica de València, Edificio 6D, 46022, Valencia, Spain.
}

\begin{abstract}
In this work, the effect of high injection pressures and ambient gas properties on diesel spray penetration and spreading angle are studied. To this end a multi-hole piezoelectric injector was used, and MIE-Scattering optical technique to visualize the spray. Injection pressures up to $270 \mathrm{MPa}$ were used throughout the experiments. Additionally, the spray behavior going from subsonic to supersonic state was analyzed by controlling the ambient gas speed of sound, promoting in this way supersonic jets. For this purpose, measurements were done using three different ambient gases $\left(\mathrm{SF}_{6}, \mathrm{CO}_{2}\right.$, and $\left.\mathrm{N}_{2}\right)$ at isothermal conditions. The results showed that sprays near transonic or in supersonic state had a higher penetration rate than those in subsonic state. Furthermore, among the sprays near transonic or in supersonic state, those with higher Mach number had faster penetration. Differently, within the sprays at subsonic state, no significant variations in spray penetration rate were found, regardless of the difference in the Mach number. Shock waves appearances were pointed out as a possible explanation for the spray penetration variations observed. Finally, a statistical analysis is presented for the spray penetration under isothermal conditions and for each ambient gas.

Keywords: Diesel injection, Shock waves, Spray Penetration, Mach number, Speed of sound, MIE-scattering.
\end{abstract}

\section{Introduction}

It is known that Internal Combustion Engines have been a fundamental part in the development of the modern world. In this sense, the constant growth in their massive production has brought up attention about their efficiency, arising increasingly restrictive emission regulations throughout the years. These 5 controls have served as an incentive to the several improvements achieved in the matter (Johnson, 2012).

\footnotetext{
*Corresponding author. E-mail address: giraldo@fev.com

Email addresses: rpayri@mot.upv.es (Raúl Payri), pedmar15@mot.upv.es (Pedro Martí-Aldaraví), tomonpr@mot.upv.es
} (Tomas Montiel) 


$\begin{array}{ll}\text { Nomenclature } \\ \text { ASOE } & \text { After start of energizing } \\ P_{\text {back }} & \text { Back Pressure } \\ \mathrm{CO}_{2} & \text { Carbon dioxide } \\ \mathrm{CI} & \text { Confidence interval } \\ \mathrm{D}_{o} & \text { Hole outlet diameter } \\ P_{i n j} & \text { Injection pressure } \\ \mathrm{M} & \text { Mach number } \\ \mathrm{N}_{2} & \text { Nitrogen }\end{array}$

$\begin{array}{ll}C_{p, l i q} & \text { Specific heat liquid fuel } \\ \mathrm{S} & \text { Spray tip penetration } \\ \mathrm{SOI} & \text { Start of injection } \\ \mathrm{SF}_{6} & \text { Sulfur hexafluoride } \\ \text { Greek } & \text { symbols } \\ \rho & \text { Ambient density } \\ \theta & \text { Spray spreading angle } \\ \Delta P & P_{i n j}-P_{b a c k}\end{array}$

Within these improvements, multi-hole injectors are being increasingly employed in the present days, given their ability to develop a more homogeneous mixture and decrease the droplet size through smaller orifice diameter, enlarging the liquid-gas contact surface (Lee et al., 2011). These qualities offer many benefits in the injection process, improving the combustion behavior and soot emissions (Lee, T 2011), which are significantly affected by the spray atomization process. However, the spray behavior of multi-hole injectors is not fully identified yet (Aori et al. 2016), and the characterization of these injectors is still a topic of interest in the engine community (Zhou et al. 2016). Certainly, multiple studies of single-hole injector's spray have been made, but the jet-jet interaction is a factor that could change the spray behavior, and it is being addressed nowadays (Bazyn and Koci, 2014, Rusly et al. 2014).

Another significant tendency towards combustion efficiency improvement is the use of higher injection pressures. Over the past few decades, the injection pressure of the common rail system has been going up. Nowadays, the injection pressure of commercial injection systems have reached up to $250 \mathrm{MPa}$, and 400 $\mathrm{MPa}$ in the laboratory (Huang et al.). In this sense, super-high (250-300 MPa) or even ultra-high (>300 $\mathrm{MPa}$ ) injection pressures may be employed commercially soon (Payri et al., 2016b).

Certainly, increasing the injection pressure is considered a highly efficient method to improve fuel economy, produce better air-fuel mixtures, and lower exhaust emissions. Nishida et al. (2017) suggest that the combination of micro-holes nozzles and ultra-high injection pressures can provide an effective way to reduce soot formation in the combustion chamber of the diesel engine, since this combination avoids the interference of liquid length and lift-off length.

Wang et al. (2011) evaluated experimentally and analytically the spray characteristics of bio-diesels and diesel under ultra-high injection pressures up to $300 \mathrm{MPa}$ and non-evaporating conditions. They con- 
Published as: Atomization and Sprays, 2018, Vol 28(12), pp. 1145-1160. DOI: 10.1615/AtomizSpr.2019029651.

cluded that high injection pressures are an effective way to mitigate the poor atomization characteristics of biodiesels. They stated as well that spreading spray angle was less affected by the injection pressure, an observation also reported by Jia et al. $(2016)$.

Delacourt et al. (2005) investigated the effect of injection pressure (up to $250 \mathrm{MPa}$ ) on the macroscopic spray characteristics, proving that correlations from Siebers (1998); Hiroyasu and Arai (1990) still described penetration trends correctly. $\mathrm{Xu}$ et al. (2017) made studies within the same range of injection pressures, under evaporative and non-evaporative conditions, stating that no significant variations on macroscopic characteristics were found. Nevertheless, they concluded that an increase of injection pressure improves the injector response sensitivity: when the injection pressure was elevated from $50 \mathrm{MPa}$ to $250 \mathrm{MPa}$, the response time and the injection cut time were reduce by $58 \%$ and $49 \%$ respectively. With these injection pressure magnitudes, spray velocity has also reached very high values, and the possibility of the spray reaching the local speed of sound (and its influence in the spray development) is a factor that is being taken into account.

Lee et al. (2005) characterized a free diesel spray from a single-hole injector with injection pressures up to $300 \mathrm{MPa}$. The spray was visualized by the Schlieren technique and a high-speed camera, and it was found that shock waves are present and propagated along the edge's spray in the downstream direction. Jia et al. (2016) carried out an experimental study to investigate the effects of ultra-high injection pressure on the penetration characteristics of diesel sprays. They affirmed that a leading edge shock wave is generated after the spray exited the nozzle, followed by multiple shock waves shock waves around the spray body at a later 45 stage.

Jia et al. (2017) also stated that the morphology of the leading shock wave changed with increasing injection pressure and spray velocity, going from a "spherical shock wave" to an "oblique shock wave". Also, these authors showed that as the injection pressure went higher, the measured spray penetration increased gradually, but its increasing rate decreased.

Along with the injection pressure, the ambient where the jet enters also plays an important role in the spray development. In this area, it is generally accepted in the research community that the behavior of the spray depends on the ambient density, not on the ambient pressure (Siebers, 1998). However, the effect of ambient gas properties over macroscopic characteristics of the spray is not very well known. Some studies have found interesting variations in spray structure by modifying the ambient gas used, using single-hole nozzles:

Payri et al. (2005) found variations in spray penetration when switching from $\mathrm{N}_{2}$ to $\mathrm{SF}_{6}$, which may have been related to the different speed of sound in each gas, achieving a transonic state in the $\mathrm{SF}_{6}$ atmosphere. 
Published as: Atomization and Sprays, 2018, Vol 28(12), pp. 1145-1160. DOI: 10.1615/AtomizSpr.2019029651.

However, different illumination set-ups and test rigs were used for each gas, so it was not possible to be conclusive about the differences observed. Later on, Payri et al. (2014) found similar variations using $\mathrm{N}_{2}$ and $\mathrm{SF}_{6}$ again, employing the same test rig and illumination this time. However, they only compared spray penetration at $7.6 \mathrm{~kg} / \mathrm{m}^{3}$ of ambient density and injection pressures up to $150 \mathrm{MPa}$. Huang et al. (2015) used the same gases, enhancing shock waves appearances in the SF6 environment. Differences in the spray behavior were observed, although the injection pressure range was from 60 to $120 \mathrm{MPa}$.

In these studies, only two ambient gases were analyzed. As only $\mathrm{N}_{2}$ achieved subsonic velocity values, it was not possible to compare non-shock wave states in different gas atmospheres, which might provide better verification for these studies.

Although certain investigations have been made, the effects of high injection pressures and ambient gas properties on the macroscopic characteristics of the diesel spray have not been extensively studied and defined. To observe these effects, in this study the spray penetration and spreading angle were analyzed under a wide range of injection pressures (up to $270 \mathrm{MPa}$ ) and ambient densities. These tests were done with a multi-hole piezoelectric injector in three different ambient gases $\left(\mathrm{SF}_{6}, \mathrm{CO}_{2}, \mathrm{~N}_{2}\right)$ under isothermal conditions, employing the same optical set-up and test rig throughout the measurements.

\section{Experimental materials and methods}

\subsection{Injection system}

The fuel feeding system consisted of a high-pressure volumetric pump (Bosch CP4), driven by an electric motor and a common-rail with a pressure regulator controlled by a PID system. Two rails were installed within the circuit in order to solve problems with high-pressure fittings and, at the same time, to increase the fuel volume available at high pressure, reducing the fluctuation due to the pump cycles. This system can generate rail pressures of up to $300 \mathrm{MPa}$ and maintain it at the set value while injecting fuel.

The injection pressure was regulated by the Engine Control Unit (ECU), which also sends the electric signal to the injector in the experiments. The returning fuel temperature was controlled by an intercooler placed between the returning lines and the fuel tank. A similar injection system was employed in Payri et al. (2016b).

All experiments were performed with a seven holes piezo-electric actuated injector able to reach up to 270 MPa. Finally, commercial Diesel fuel was used (EU standard EN590). Fuel properties relevant to this study are summarized in Table 1 (Lemmon et al. 2011). 
Table 1: Fuel properties at $313 \mathrm{~K}$ and $101 \mathrm{KPa}$.

\begin{tabular}{cc}
\hline Property & Value \\
\hline Density $\left(\mathrm{Kg} / \mathrm{m}^{3}\right)$ & 812 \\
Kinematic viscosity $\left(\mathrm{mm}^{2} / \mathrm{s}\right)$ & 2.03 \\
Surface tension $(\mathrm{N} / \mathrm{m})$ & 0,022 \\
Boiling point $(\mathrm{K})$ & $450-520$ \\
$C_{p, l i q}(\mathrm{~J} / \mathrm{kg} \mathrm{K})$ & 2002 \\
\hline
\end{tabular}

\subsection{Spray isolation and alignment}

As the measurements were done with a multi-hole injector, the spray of interest had to be aligned and isolated from the other jets. For this purpose, the same isolation device and methodology used by Payri spray of interest, preventing them from impinging the test rig windows or interfering in the camera line of sight. This technique was elected over blocking the holes, as this obstructions change the internal nozzle flow and thereby the spray structure (Gavaises and Andriotis, 2006). The neighbor jets of the spray of interest were not contained (Figure 1) so that the spray of interest would develop in a more realistic environment.

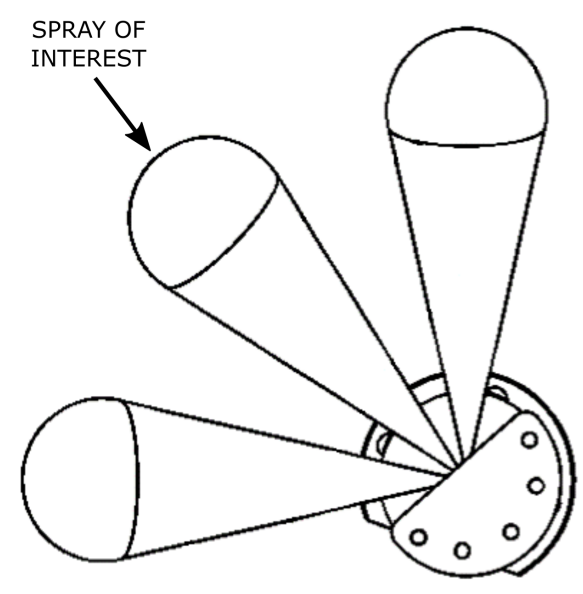

Figure 1: Device for spray isolation. The chamber contains all jets except the spray of interest and its neighbors.

\subsection{Test rig and optical set-up}

The test rig used in this work was designed to visualize the spray at ambient temperature and high ambient density conditions. The facility offers better optical access than a standard engine and can reproduce the ambient density from the combustion chamber at the moment of the injection. This is a useful capability, 
as the chamber density has a strong influence on the behavior of non-evaporative sprays (Payri et al., 2008a the injected fuel and then across a root compressor that sends it back to the testing chamber. The test rig windows dimensions allowed to characterize the spray penetration up to $70 \mathrm{~mm}$. This installation (Figure 2a. has been used and described in previous works (Payri et al., 2016b, 2014, Pastor et al., 2007).

The imaging technique employed in the experiments was MIE-scattering, widely used and described by the engine community for the visualization of the fuel spray liquid phase (Siebers, 1998: Payri et al., 2008b: Pickett et al., 2011). It consists in illuminating the fuel droplets with a light source (pulsed or continuous) and collecting the scattered light with a camera (Figure 2b).

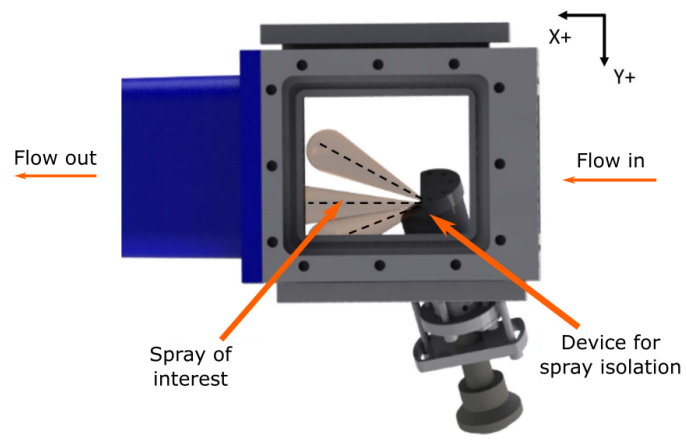

(a)

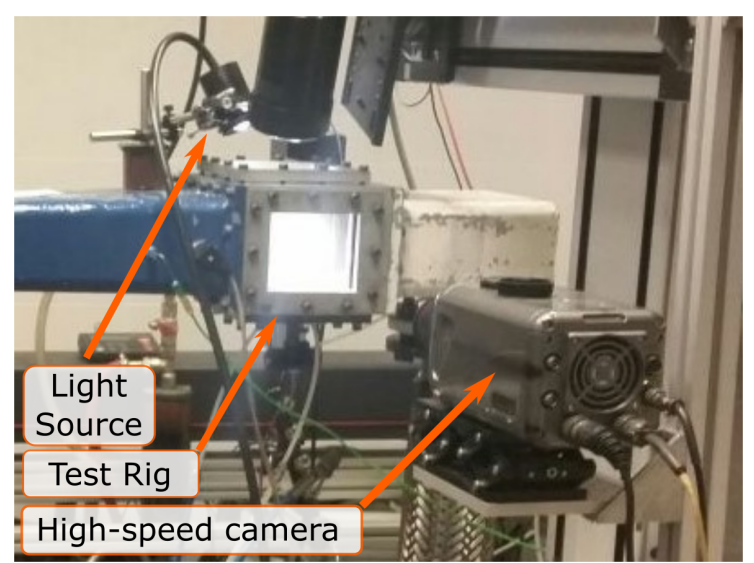

(b)

Figure 2: Test rig used throughout the measurements.

Images were taken with a high-speed CMOS camera Phantom V12, equipped with a $100 \mathrm{~mm}$ focal length ZEISS lens, an image resolution of $689 \times 304$ pixels, and 18.000 fps. Each pixel corresponded to $3.1 \mathrm{~mm}$. The illumination used was a continuous light source provided by a $150 \mathrm{~W}$ quartz-halogen illuminator (DolanJenner PL800), supplied by $8 \mathrm{~mm}$ optic fiber bundles. The light source was positioned above the test rig at $200 \mathrm{~mm}$ from the spray, sharply collimated and focused on the studied area, so that an evenly distributed light was distributed throughout the spray of interest.

\section{4. image processing}

The algorithm used to process the images is described in Payri et al. (2016c, 2013); Macian et al. (2012). Nevertheless, the procedure can be summarized in three steps. First, a mask is applied to isolate the spray of interest from the other jets. Afterward, images are binarized with a threshold that is calculated as $3 \%$ of 
the dynamic range of the current frame. Lastly, the spray contour is extracted through a pixel-connectivity evaluation (Figure 3).

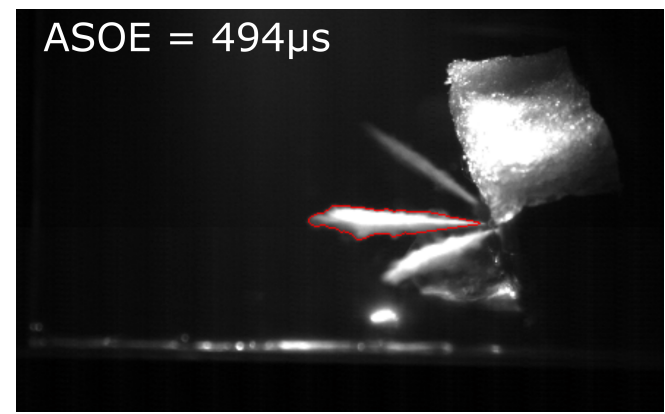

(a)

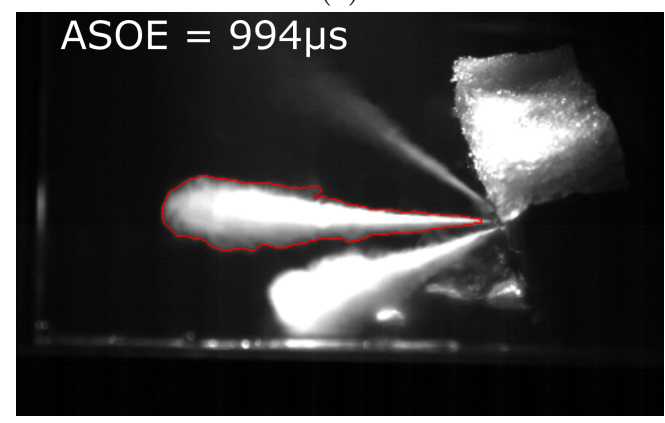

(c)

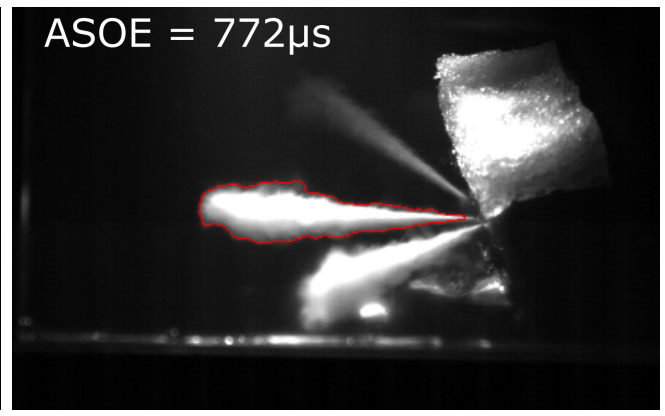

(b)

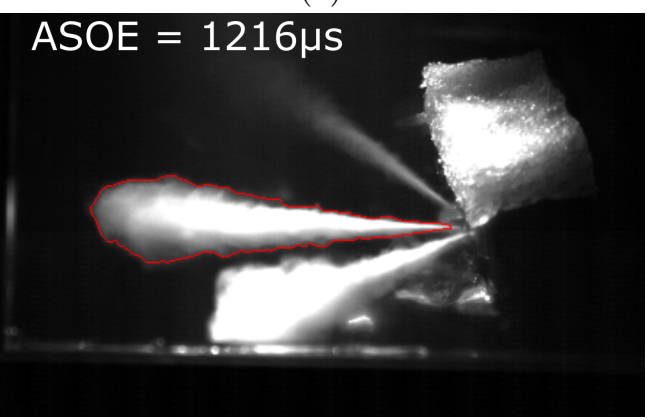

(d)

Figure 3: Evolution of high injection pressure spray. Ambient gas: $\mathrm{SF}_{6}, P_{i n j}=270 \mathrm{MPa}, \rho=15.2 \mathrm{Kg} / \mathrm{m}^{3}$

Then, spray penetration is calculated as the linear distance from the nozzle outlet to the furthest pixel of the spray contour (Figure 4) (Payri et al., 2016a). Additionally, spray spreading angle is calculated from two straight lines that are adjusted to the spray contour that is within $25 \%$ and $60 \%$ of spray penetration, and that converge to the hole exit.

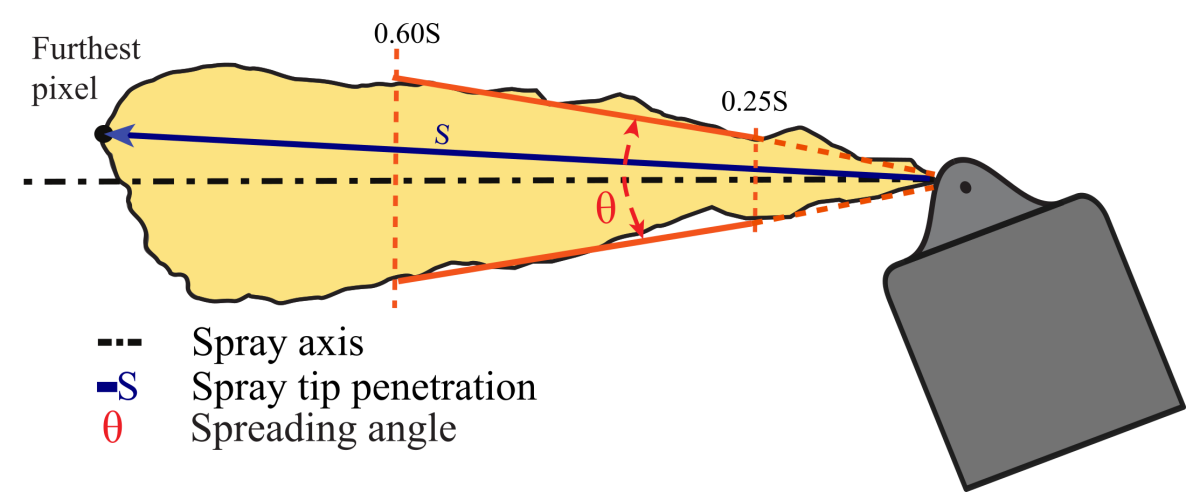

Figure 4: Schematic diagram of the spray. 


\subsection{Test plan} ambient pressures, a high molecular weight gas like $\mathrm{SF}_{6}$ was used (Payri et al., 2012, Huang et al., 2015. Desantes et al. 2005). Furthermore, to explore the effects of shock waves appearance at non-evaporative conditions, supersonic jets were enhanced by controlling the ambient gas speed of sound. To this end, three ambient gases with different speed of sound were tested (Table 2).

Table 2: Speed of sound of gases used in non-evaporative measurements.

\begin{tabular}{ccc}
\hline Gas & Speed of sound $[\mathbf{m} / \mathbf{s}]$ & Molecular weight $[\mathrm{g} / \mathbf{m o l}]$ \\
\hline $\mathrm{SF}_{6}$ & 129.8 & 146,06 \\
$\mathrm{CO}_{2}$ & 256.5 & 44,01 \\
$\mathrm{~N}_{2}$ & 352.5 & 28,01 \\
\hline
\end{tabular}

A resume of the test matrix is presented in Table 3, where the same range of injection pressure values were covered with the three gases. The highest ambient pressure allowed in the test rig was $0.9 \mathrm{MPa}$, so the maximum ambient density achievable varied between gases.

Table 3 also includes the estimated spray tip state. It was calculated employing the theoretical velocity from Bernoulli's equation, and an arbitrary factor that takes into account the discharge coefficient and the drop with axial distance in the spray velocity, as a result of the air entrainment along the spray evolution (Pastor et al. 2008; Payri et al. 2018).

Table 3: Experimental conditions for isothermal sprays.

\begin{tabular}{cccc}
\hline Ambient Gas & Ambient density $\left[\mathbf{K g} / \mathbf{m}^{3}\right]$ & Injection pressure [MPa] & State \\
\hline \multirow{2}{*}{$\mathbf{S F}_{6}$} & $3 / 7.6 / 10.8 / 15.2 / 22.8 / 30.4$ & $25 / 35$ & Subsonic \\
& & $50 / 90$ & Transonic \\
& \multirow{2}{*}{$\mathbf{C O}_{2}$} & $150 / 200 / 270$ & Supersonic \\
\hline $\mathbf{N}_{2}$ & $3 / 7.6 / 10.8 / 15.2$ & $25 / 35 / 50 / 90 / 150$ & Subsonic \\
\hline
\end{tabular}

The ambient temperature was kept constant at $293 \mathrm{~K}$ during the whole measurements, and the energizing time was $1 \mathrm{~ms}$ in all the injections. For each operating point, ten repetitions were acquired and analyzed. 


\section{Results and discussions}

\subsection{Effect of ambient density and injection pressure on spray penetration and spreading angle}

The most noticeable trends from macroscopic characterization under non-evaporative environment are depicted in Figure 5. An increase in ambient density caused a decrease in the spray penetration rate due to a greater momentum loss, resulting in slower penetration. Also, higher injection pressures produced an increment in the spray penetration, related to the bigger momentum of the spray. Many others researches have observed these trends (Bardi et al., 2012, Ha et al., 1983, Naber and Siebers, 1996, Payri et al., 2011).

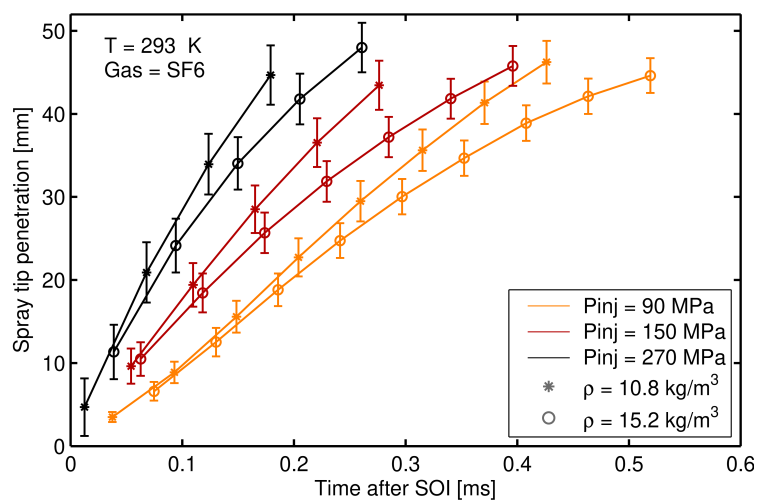

(a)

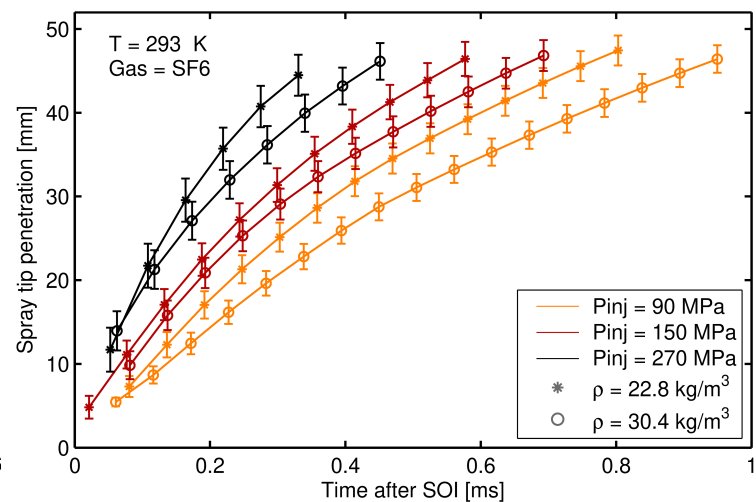

(b)

Figure 5: Spray tip penetration at isothermal conditions. A slower spray penetration is reported as the ambient density increases.

Regarding the spreading angle measurements, increasing the ambient density caused a wider spreading angle, while elevating the injection pressure reduced it (Figure 6). Nevertheless, the effect of the ambient density on this parameter appears to be higher than the effect of the injection pressure. It has to be said that the conclusion drawn here concerning the influence of the ambient density and injection pressure on the spreading angle has already been formulated by other researchers (Naber and Siebers, 1996, Hiroyasu and Arai, 1990).

However, care must be taken when analyzing these angle measurements because the parameters used during image processing affect the resulting spreading angle widely. For instance, the total standard deviation on the spreading angle for the reference testing conditions $\left(P_{i n j}=50 \mathrm{MPa}, \rho=22.8 \mathrm{~kg} / \mathrm{m}^{3}\right)$ is 1.5 degrees, which represents about $9.7 \%$ of the measured spreading angle at those conditions: $\theta=15.45$ degrees. Therefore the results regarding the spreading angle should be taken as qualitative and not quantitative measurements. 


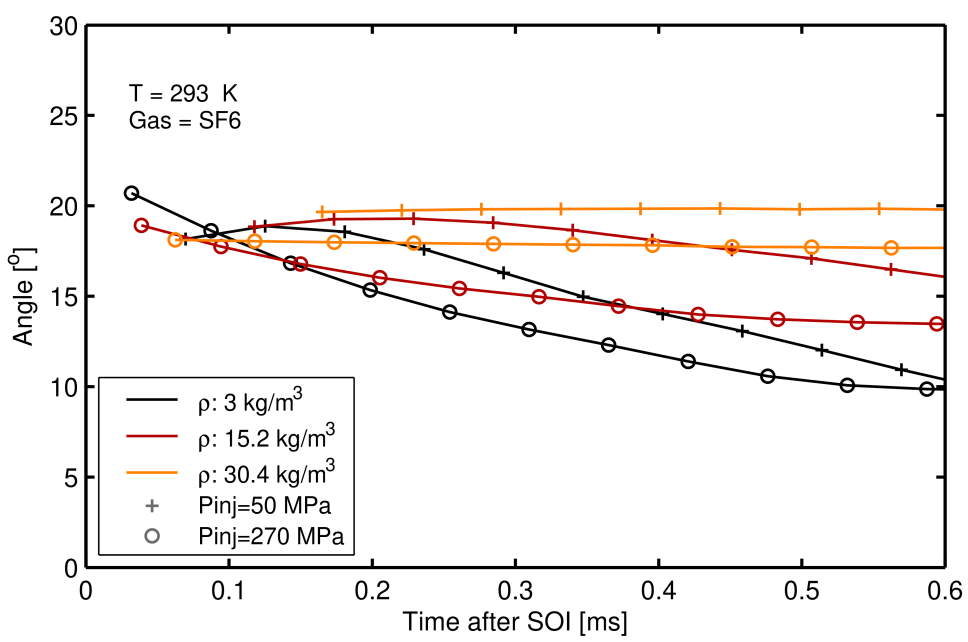

Figure 6: Spray spreading angle at isothermal conditions. Elevating the ambient density causes a increment in the spray angle.

In order to quantify the effect of each test conditions, the data obtained in the tests in the $\mathrm{SF}_{6}$ atmosphere were used for statistical analysis. The equation employed for the regression was the one used in Payri et al.

$$
S=k \rho^{a} \Delta P^{b} \tan (\theta / 2)^{c} D_{o}^{d} t^{e}
$$

To observe the real effect of high injection pressures on spray penetration development, two correlations were obtained. The first of them (Fit A) included high injection pressures (up to $270 \mathrm{MPa}$ ), and the second (Fit B) one did not (up to $200 \mathrm{MPa}$ ).

The results shown in Table 4 demonstrate that all parameters included in the correlations play an important role. It can be observed that in both cases a good fit to the experimental data is found, as the R-squared value in both cases suggests high confidence in the correlations results from the statistics point of view. Furthermore, the experimental results appear to be consistent with previous research in diesel spray characterizations at low and high ambient densities, as the exponents fall within the intervals proposed by Naber and Siebers (1996).

Comparing both correlations the exponents did not vary considerably, which allows us to think that the very high injection pressure effects over macroscopic characteristics are still the same. Furthermore, all the exponents obtained from the Fit B fall into the confidence interval (CI) from the Fit A, and vice versa. 
Table 4: Exponents from Eq. 1 estimated in tests under $\mathrm{SF}_{6}$.

\begin{tabular}{ccccc}
\hline Exponent & Fit A for Eq. 1 & CI for Fit A & Fit B for Eq. 1] & CI for Fit B \\
\hline$k$ & 0.4242 & {$[0.4173,0.4311]$} & 0.418 & {$[0.4109,0.425]$} \\
$a$ & -0.1673 & {$[-0.1795,-0.1551]$} & -0.1575 & {$[-0.1696,-0.1454]$} \\
$b$ & 0.2935 & {$[0.2874,0.2996]$} & 0.2887 & {$[0.2824,0.2949]$} \\
$c$ & -0.5876 & {$[-0.6145,-0.5607]$} & -0.6018 & {$[-0.6281,-0.5755]$} \\
$d$ & 0.4688 & {$[0.4546,0.4831]$} & 0.4663 & {$[0.4518,0.4870]$} \\
$e$ & 0.5434 & {$[0.5353,05516]$} & 0.5481 & {$[0.5402,0.5561]$} \\
$R^{2}$ & $98,06 \%$ & - & $98.25 \%$ & - \\
\hline
\end{tabular}

\subsection{Effect of gas properties on spray penetration and spreading angle.}

The goal of this section is to explore the spray development in different ambient gases using the same test rig, illumination, and optical set-up. As it has been said before, three different gases $\left(\mathrm{N}_{2}, \mathrm{CO}_{2}\right.$, and $\mathrm{SF}_{6}$ ) with different speed of sounds were used.

In Figure 7 the effect of the ambient gas over spray tip penetration is depicted. An interesting trend is that at the same ambient density the spray penetration grew faster under the $\mathrm{SF}_{6}$ atmosphere. A similar tendency was also observed by Payri et al. (2014) using $\mathrm{SF}_{6}$ and $\mathrm{N}_{2}$. However, they only compared spray penetration at $7.6 \mathrm{~kg} / \mathrm{m}^{3}$ of ambient density, injection pressures up to $150 \mathrm{MPa}$, and for two ambient gases only.

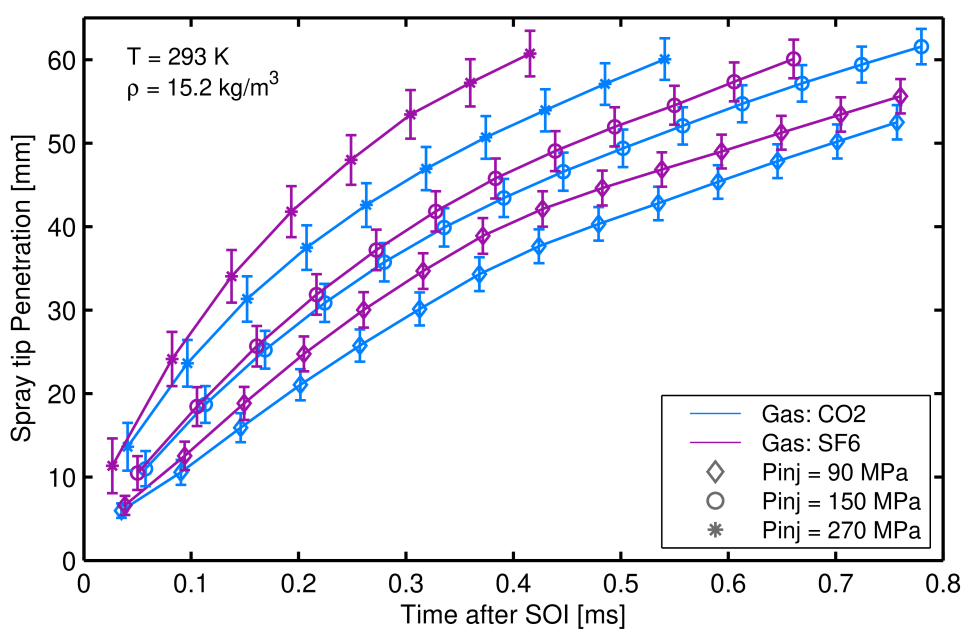

Figure 7: Spray tip penetration in different ambient gases.

One possible explanation of the differences observed in the spray penetration rate in Figure 7 , could be the different $\Delta P$ required to achieve the desired density for each gas (due to molecular weight differences, $\mathrm{CO}_{2}$ need to be compressed much more). However, reviewing the coefficients on Table 4 , the influence of 

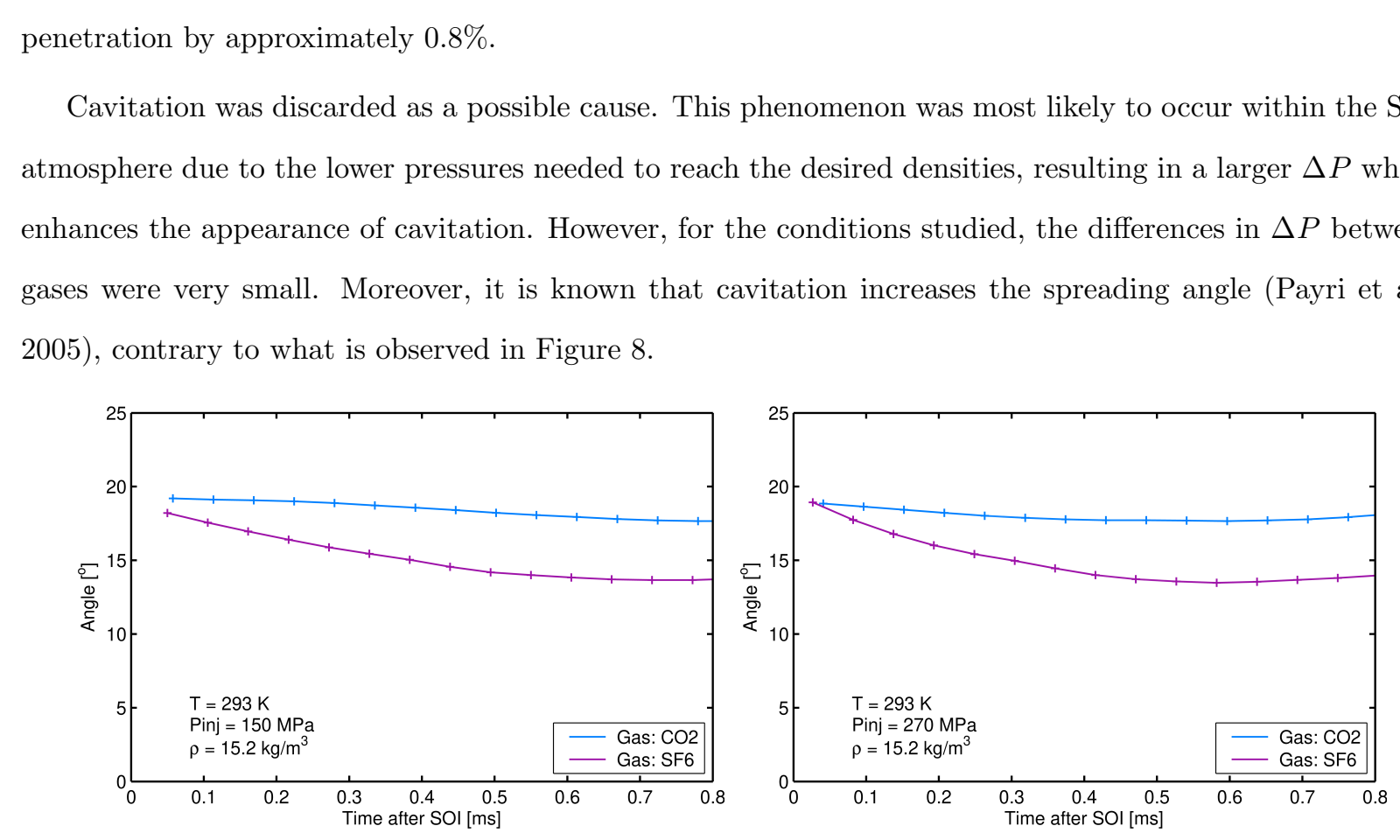

Figure 8: Effect of gas properties on spray spreading angle.

Furthermore, the spray reaching supersonic state was explored as a possible explanation. To this end, the spray tip Mach number of the penetration curves was calculated. Specifically, the spray tip velocity was determined by numerical differentiation of the spray tip penetration in time, and the tip Mach number was obtained with the ratio between this velocity and the speed of sound for each gas. In Figure 9 , it can be observed that curves under $\mathrm{SF}_{6}$ atmosphere were near transonic or in supersonic state $(0.8>M)$, whereas the curves under $\mathrm{CO}_{2}$ did not.

Additionally, Figure 10 shows the spray tip penetration and Mach number under the three ambient gases used in the experiments. Once more, spray penetration grew faster within the $\mathrm{SF}_{6}$ atmosphere than the others. Also, curves under $\mathrm{CO}_{2}$ atmosphere near transonic state $(0.8<M<1.2)$ have a faster penetration rate than $\mathrm{N}_{2}$ curves. 


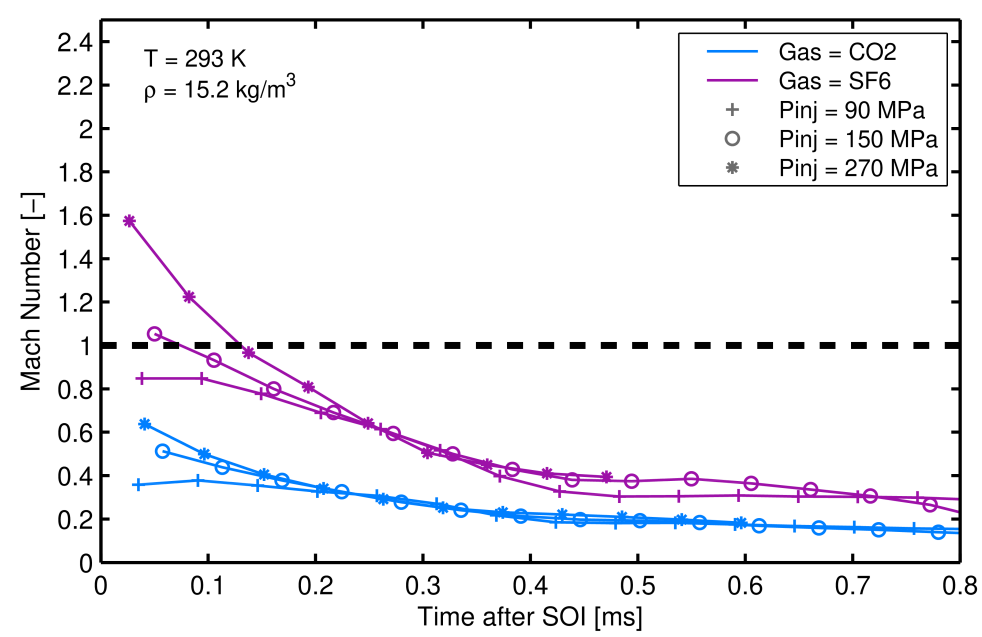

Figure 9: Spray tip penetration in different ambient gases.
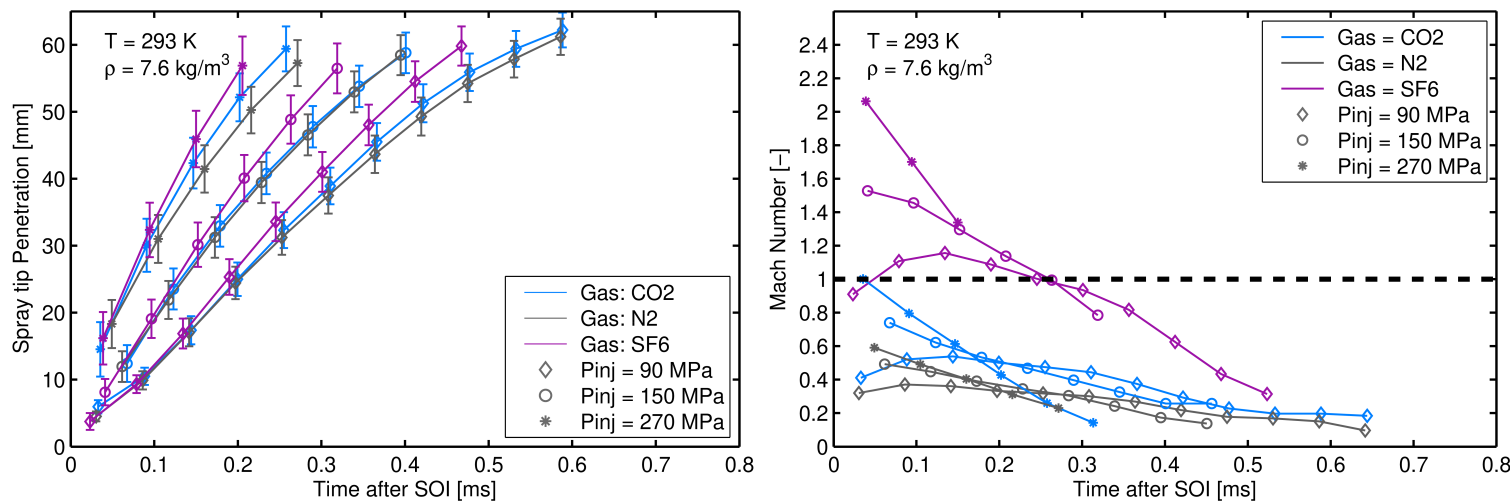

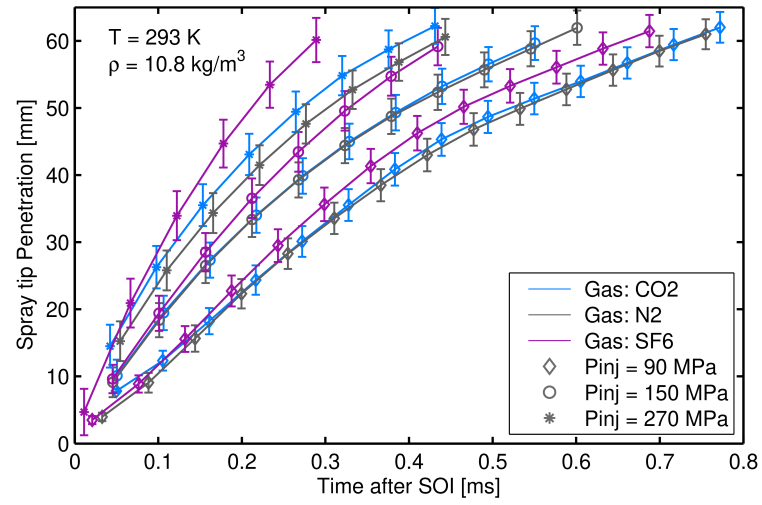

(a) Spray tip penetration.

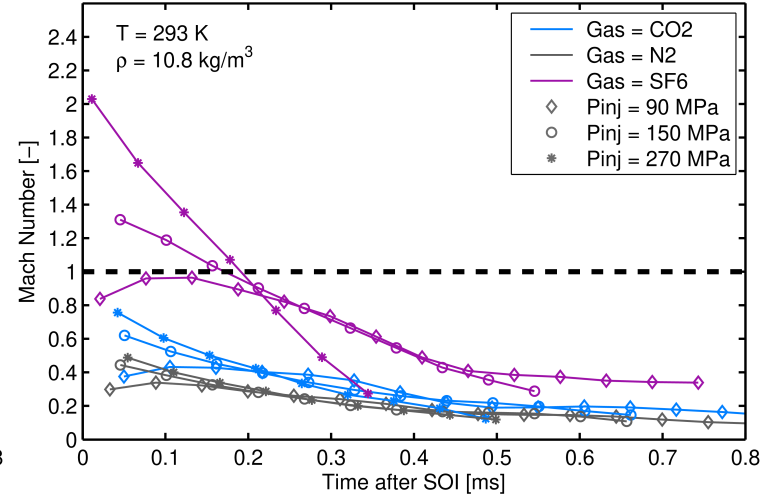

(b) Spray tip Mach number.

Figure 10: Spray tip penetration and Mach number at isothermal conditions. Sprays tip near transonic or supersonic state $(0.8>M)$ had a faster penetration rate than those in the subsonic state.

After discarding other possible explanations of the spray penetration difference, it could be attributed 
Published as: Atomization and Sprays, 2018, Vol 28(12), pp. 1145-1160. DOI: 10.1615/AtomizSpr.2019029651.

to the generated shock waves in the transition stage of penetration from subsonic to supersonic state in $\mathrm{SF}_{6}$ and $\mathrm{CO}_{2}$ atmospheres, which is unlikely to happen under $\mathrm{N}_{2}$ atmosphere in the range of pressures that has been tested, since the maximum Mach number was 0.6.

In this sense, Roisman et al. (2007) studied the importance of the interaction between the spray jet and the shock waves that appear in the ambient gas. They stated that the initially compressed gas behind the shock wave would expand as the spray cross-section enlarged, creating a depression zone that would enhance a faster spray penetration.

Huang et al. (2015) reported the appearance of shock waves even though the spray tip velocity had not reached the local sound speed. They reported that nozzle exit velocity values are higher than spray tip velocity values, so employing nozzle exit velocity values could predict shock waves appearance that spray tip velocity would not. This observation would explain the higher penetration rate of the spray under the $\mathrm{CO}_{2}$ atmosphere curves near the local speed of sound, since the velocity in these measurements was calculated at the spray tip.

Additionally, differences can be observed in the spray penetration rate among the jets near transonic or in supersonic state in different ambient gases. Specifically, sprays under $\mathrm{SF}_{6}$ atmosphere had a faster penetration than those under $\mathrm{CO}_{2}$ atmosphere near transonic state (Figure 10a). This variation might be due to differences of the shock wave shape in the two ambient gases. As the sprays under $\mathrm{SF}_{6}$ had a bigger Mach number, an "oblique" shaped shock wave should appear at the spray front (Jia et al., 2017), which affects the density near the shock wave in a different way than "spherical" shaped shock waves Anderson Jr. 2002). On the contrary, jets under subsonic state in different ambient gases $\left(\mathrm{CO}_{2}\right.$ and $\left.\mathrm{N}_{2}\right)$ did not show major differences in the spray penetration, regardless of the difference in Mach number values.

Furthermore, experiments for $\mathrm{CO}_{2}$ and $\mathrm{N}_{2}$ are also fitted with the Equation 1, and the exponents obtained from these fittings are displayed in Table 5. Since the subsonic state was achieved in more occasions under $\mathrm{CO}_{2}$ atmosphere than within $\mathrm{SF}_{6}$, the coefficients are closer between the correlations developed for $\mathrm{CO}_{2}$ and $\mathrm{N}_{2}$ atmosphere than for $\mathrm{SF}_{6}$ and $\mathrm{N}_{2}$.

Lastly, figure 11 show the observed penetration for each ambient gas, compared to those predicted by the regression. It can be seen how the penetration is especially well predicted in the full developed part of the spray (after 20mm) in all cases, where the ambient has the strongest influence over the penetration. 
Table 5: Exponents from Eq. 1 estimated in tests under $\mathrm{CO}_{2}$ and $\mathrm{N}_{2}$ atmosphere.

\begin{tabular}{ccccc}
\hline Exponent & Fit under $\mathbf{C O}_{2}$ & $\mathbf{C I}$ under $\mathbf{N}_{2}$ & Fit under $\mathbf{C O}_{2}$ & $\mathbf{C I}$ under $\mathbf{N}_{2}$ \\
\hline$k$ & 0.2502 & {$[0.2329,0.2676]$} & 0.3088 & {$[0.2861,0.3315]$} \\
$a$ & -0.1109 & {$[-0.1295,-0.0922]$} & -0.2096 & {$[-0.2297,-0.1395]$} \\
$b$ & 0.3669 & {$[0.3561,0.3776]$} & 0.3983 & {$[0.3828,0.4138]$} \\
$c$ & -0.7554 & {$[-0.8057,-0.7022]$} & -0.6001 & {$[-0.6693,-0.5309]$} \\
$d$ & 0.3852 & {$[0.3641,0.4063]$} & 0.4162 & {$[0.3821,0.4503]$} \\
$e$ & 0.5366 & {$[0.5206,0.5527]$} & 0.5950 & {$[0.5704,0.6195]$} \\
$R^{2}$ & $97.29 \%$ & - & $97.73 \%$ & - \\
\hline
\end{tabular}

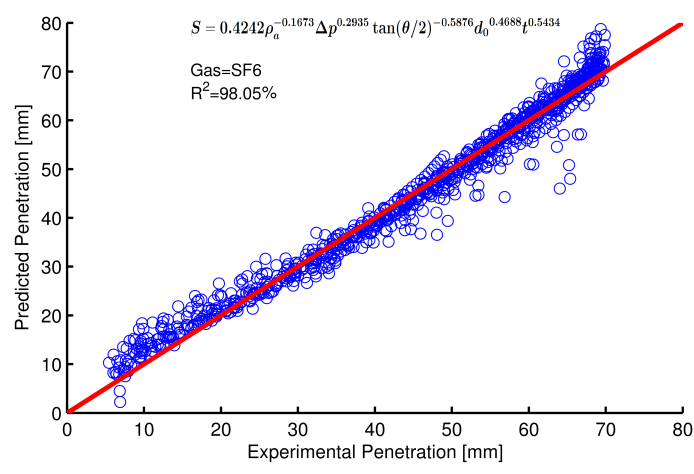

(a) $\mathrm{SF}_{6}$

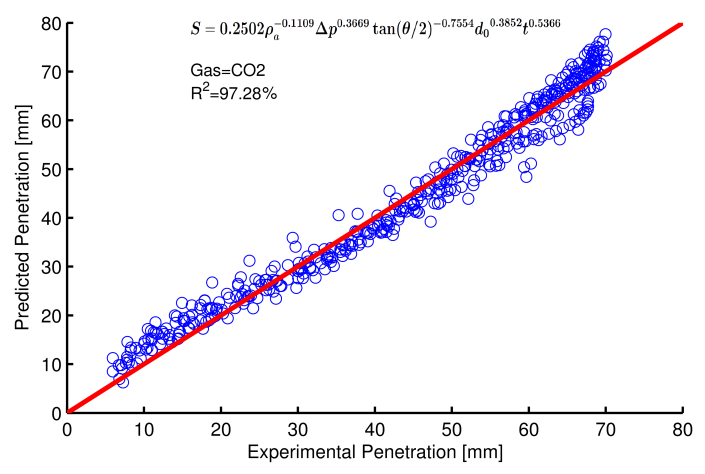

(b) $\mathrm{CO}_{2}$

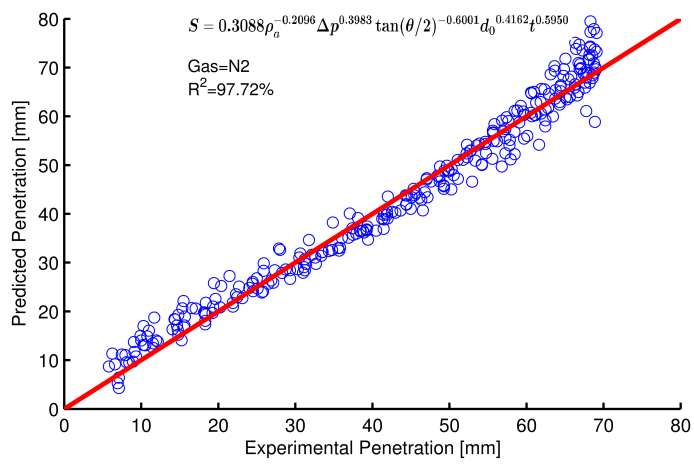

(c) $\mathrm{N}_{2}$

Figure 11: Experimental penetration versus predicted penetration by Equation 1, considering the exponents of Tables 4 and 5 . 
Published as: Atomization and Sprays, 2018, Vol 28(12), pp. 1145-1160. DOI: 10.1615/AtomizSpr.2019029651.

\section{Conclusions}

From the measurements done, the following main conclusions are drawn:

- As expected, ambient density was a critical parameter for the spray development, and it affected both spray penetration and spreading angle. The increment of ambient density caused an increase in the spray spreading angle and at the same time, a slower spray penetration.

- Two empirical predictive models for spray penetration under isothermal conditions under $\mathrm{SF}_{6}$ atmosphere were presented, one of them including very high injection pressures. There were no significant differences between the fitted data including very high injection pressures (up to $270 \mathrm{MPa}$ ) and medium pressures (up to $200 \mathrm{MPa}$ ). Thus, for the $\mathrm{SF}_{6}$ atmosphere, the influence of ambient and injection parameters kept the same behavior for pressures up to $270 \mathrm{MPa}$.

- At same ambient densities spray penetration grew faster within the $\mathrm{SF}_{6}$ atmosphere than the others $\left(\mathrm{CO}_{2}\right.$ and $\left.\mathrm{N}_{2}\right)$ and had smaller spray spreading angle. After effectively discarding $\Delta P$ and cavitation as causes, shock waves appearances was pointed out as the possible explanation. In this sense, the initially compressed gas behind the shock would expand as the spray develops, creating a depression zone which enhances the spray penetration.

- Sprays tip near transonic or in supersonic state $(0.8>M)$ had a faster penetration rate than those in the subsonic state. Furthermore, spray penetration under different ambient gases $\left(\mathrm{SF}_{6}\right.$ and $\left.\mathrm{CO}_{2}\right)$ in the transonic or supersonic state was compared. Sprays under $\mathrm{SF}_{6}$ atmosphere had a faster penetration than those under $\mathrm{CO}_{2}$ atmosphere. This variation might be due to the difference of the shock wave shape in the two ambient gases. As the sprays under $\mathrm{SF}_{6}$ had a bigger Mach number, a more oblique shaped shock wave should appear at the spray front. Differently, spray penetration under different ambient gases $\left(\mathrm{CO}_{2}\right.$ and $\left.\mathrm{N}_{2}\right)$ in the subsonic state was compared and no significant differences were observed, regardless of the difference in Mach number values.

- Spray penetration correlations under $\mathrm{CO}_{2}$ and $\mathrm{N}_{2}$ atmosphere were reported and compared with the correlation under $\mathrm{SF}_{6}$ atmosphere. The coefficients in the correlations were more similar between the $\mathrm{CO}_{2}$ and $\mathrm{N}_{2}$ atmosphere predictive models than between $\mathrm{CO}_{2}$ or $\mathrm{N}_{2}$, and $\mathrm{SF}_{6}$. These reports were attributed to the similarities of the gas properties between $\mathrm{CO}_{2}$ and $\mathrm{N}_{2}$. Differently, the spray developed under $\mathrm{SF}_{6}$ atmosphere confronted a much lower local speed of sound, achieving the supersonic state constantly. 
Published as: Atomization and Sprays, 2018, Vol 28(12), pp. 1145-1160. DOI: 10.1615/AtomizSpr.2019029651.

\section{Acknowledgements}

The equipment used for the experiments was financially supported by IDIFEDER2018 from Generalitat Valenciana. Also, Tomas Montiel was supported by a research grant from Generalitat Valenciana (Programa ACIF, ACIF /2018/122)

\section{References}

Ha, J.Y., Hayashi, A., Tanabe, H., Sato, G.T., Kuniyoshi, H., and Fujimoto, H., Investigation on the initial part and the spray formation delay of Diesel spray, SAE Technical Paper 830451, 1983. DOI: 10.4271/830451.

Hiroyasu, H. and Arai, M., Structures of Fuel Sprays in Diesel Engines, SAE Technical Paper 900475, 1990. DOI: $10.4271 / 900475$.

Huang, W., Wu, Z., Gao, Y., and Zhang, L., Effect of shock waves on the evolution of high-pressure fuel jets, Applied Energy, vol. 159, pp. 442-448, 2015. DOI: 10.1016/j.apenergy.2015.08.053.

Jia, T.M., Li, G.X., Yu, Y.S., and Xu, Y.J., Effects of ultra-high injection pressure on penetration characteristics of diesel spray and a two-mode leading edge shock wave, Experimental Thermal and Fluid Science, vol. 79, pp. 126-133, 2016. DOI: $10.1016 /$ j.expthermflusci.2016.07.006.

Jia, T.M., Yu, Y.S., and Li, G.X., Experimental investigation of effects of super high injection pressure on diesel spray and induced shock waves characteristics, Experimental Thermal and Fluid Science, vol. 85, pp. 399-408, 2017. DOI: $10.1016 /$ j.expthermflusci.2017.03.026.

Johnson, T.V., Vehicular Emissions in Review, SAE International Journal of Engines, vol. 5, no. 2, pp. 216-234, 2012. DOI: $10.4271 / 2012-01-0368$. 
Published as: Atomization and Sprays, 2018, Vol 28(12), pp. 1145-1160. DOI: 10.1615/AtomizSpr.2019029651.

Lee, S.H., Jeong, D.Y., Lee, J.T., Ryou, H.S., and Hong, K., Investigations on spray characteristics under ultra-high injection pressures conditions., International journal of automotive technology, vol. 6, no. 2, pp. 125-131, 2005. .

Lee, T., Leok, M., and McClamroch, N.H., Geometric numerical integration for complex dynamics of tethered spacecraft, Proceedings of the 2011 American Control Conference, 2011. DOI: 10.1109/ACC.2011.5990836.

Lemmon, E.W., McLinden, M.O., and Friend, D.G., 2011. Thermophysical Properties of Fluid Systems, NIST Chemistry WebBook, NIST Standard Reference Database Number 69. Linstrom, P.J. and Mallard, W.G. (Eds.). National Institute of Standards and Technology, Gaithersburg, USA. DOI: 10.18434/T4D303.

Macian, V., Payri, R., Garcia, A., and Bardi, M., Experimental Evaluation of the Best Approach for Diesel Spray Images Segmentation, Experimental Techniques, vol. 36, no. 6, pp. 26-34, 2012. DOI: 10.1111/j.1747-1567.2011.00730.x.

Naber, J.D. and Siebers, D.L., Effects of Gas Density and Vaporization on Penetration and Dispersion of Diesel Sprays, SAE Paper 960034, Vol. 105, Society of Automotive Engineers, Inc., Warrendale, Pennsylvania, USA, pp. 82-111, 1996. DOI: $10.4271 / 960034$.

Nishida, K., Jingyu, Z., Xianyin, L., and He, Z., Effects of micro-hole nozzle and ultra-high injection pressure on air entrainment, liquid penetration, flame lift-off and soot formation of diesel spray flame, International Journal of Engine Research, vol. 18, no. 1-2, pp. 51-65, 2017. DOI: 10.1177/1468087416688805.

Pastor, J.V., Arrègle, J., Garcia-Oliver, J.M., and Zapata, L.D., Segmentation of Diesel spray images with log-likelihood ratio test algorithm for non-Gaussian distributions, Applied Optics, vol. 46, no. 6, pp. 888-899, 2007. DOI: 10.1364/AO.46.000888.

Pastor, J.V., Lopez, J.J., Garcia-Oliver, J.M., and Pastor, J.M., A 1D model for the description of mixing-controlled inert diesel sprays, Fuel, vol. 87, no. 13-14, pp. 2871-2885, 2008. DOI: 10.1016/j.fuel.2008.04.017.

Payri, F., Arrègle, J., Lopez, J.J., and Hermens, S., Effect of Cavitation on the Nozzle Outlet Flow, Spray and Flame Formation in a Diesel Engine., SAE Paper 2006-01-1391, 2006. DOI: 10.4271/2006-01-1391.

Payri, F., Payri, R., Bardi, M., and Carreres, M., Engine combustion network: Influence of the gas properties on the spray penetration and spreading angle, Experimental Thermal and Fluid Science, vol. 53, pp. 236-243, 2014. DOI: $10.1016 /$ j.expthermflusci.2013.12.014.

Payri, F., Payri, R., Salvador, F.J., and Bardi, M., Effect of gas properties on Diesel spray penetration and spreading angle for the ECN injectors, ICLASS 2012, 12th Triennial International Conference on Liquid Atomization and Spray Systems, Heidelberg, 2012. .

Payri, R., Araneo, L., Shakal, J.S., and Soare, V., Phase doppler measurements: System set-up optimization for characterization of a diesel nozzle, Journal of Mechanical Science and Technology, vol. 22, no. 8, pp. 1620-1632, 2008a. DOI: 10.1007/s12206008-0432-7a.

5 Payri, R., De la Morena, J., Pagano, V., Hussain, A., Sammut, G., and Smith, L., One-dimensional modeling of the interaction between close-coupled injection events for a ballistic solenoid injector, International Journal of Engine Research, vol. 20, no. 4, pp. 452-469, 2018. DOI: 10.1177/1468087418760973.

Payri, R., Gimeno, J., Bracho, G., and Vaquerizo, D., Study of liquid and vapor phase behavior on Diesel sprays for heavy duty engine nozzles, Applied Thermal Engineering, vol. 107, pp. 365-378, 2016a. DOI: 10.1016/j.applthermaleng.2016.06.159a.

Payri, R., Gimeno, J., Martí-Aldaraví, P., and Giraldo, J.S., Methodology for Phase Doppler Anemometry Measurements on a Multi-Hole Diesel Injector, Experimental Techniques, vol. 41, no. 2, pp. 1-8, 2016b. DOI: 10.1007/s40799-016-0154-1b.

Payri, R., Gimeno, J., Viera, J.P., and Plazas, A.H., Needle lift profile influence on the vapor phase penetration for a prototype diesel direct acting piezoelectric injector, Fuel, vol. 113, pp. 257-265, 2013. DOI: 10.1016/j.fuel.2013.05.057. 
Published as: Atomization and Sprays, 2018, Vol 28(12), pp. 1145-1160. DOI: 10.1615/AtomizSpr.2019029651.

Payri, R., Salvador, F.J., Gimeno, J., and De la Morena, J., Influence of injector technology on injection and combustion development, Part 2: Combustion analysis, Applied Energy, vol. 88, no. 4, pp. 1130-1139, 2011. DOI: $10.1016 /$ j.apenergy.2010.10.012

Payri, R., Salvador, F.J., Gimeno, J., and Soare, V., Determination of diesel sprays characteristics in real engine in-cylinder air density and pressure conditions, Journal Of Mechanical Science and Technology, vol. 19, no. 11, pp. 2040-2052, 2005. DOI: $10.1007 / \mathrm{BF} 02916497$.

Payri, R., Salvador, F.J., Gimeno, J., and Viera, A., Effect of Injection Rate Shaping over Diesel Spray Development in Non-Reacting Evaporative Conditions, 10. Tagung Diesel- und Benzindirekteinspritzung 2016, Tschöke, H. and Marohn, R. (Eds.), no. 1, Springer Vieweg, Wiesbaden, Germany, pp. 133-152, 2016c. DOI: 10.1007/978-3-658-15327-4c.

Payri, R., Salvador, F.J., Gimeno, J., and Zapata, L.D., Diesel nozzle geometry influence on spray liquid-phase fuel penetration in evaporative conditions, Fuel, vol. 87, no. 7, pp. 1165-1176, 2008b. DOI: 10.1016/j.fuel.2007.05.058b.

Pickett, L.M., Genzale, C.L., Manin, J., Malbec, L.M., and Hermant, L., Measurement Uncertainty of Liquid Penetration in Evaporating Diesel Sprays, ILASS Americas, 23rd Annual Conference on Liquid Atomization and Spray Systems, ILASSAmericas, Ventura, CA (USA), 2011. .

Reitz, R.D. and Bracco, F.V., On the dependence of spray angle and other spray parameters on nozzle design and operating conditions, SAE Technical Paper 790494, 1979. DOI: 10.4271/790494.

Roisman, I., Araneo, L., and Tropea, C., Effect of ambient pressure on penetration of a diesel spray, International Journal of Multiphase Flow, vol. 33, no. 8, pp. 904-920, 2007. DOI: 10.1016/j.ijmultiphaseflow.2007.01.004.

Rusly, A.M., Le, M.K., Kook, S., and Hawkes, E.R., The shortening of lift-off length associated with jet-wall and jet-jet interaction in a small-bore optical diesel engine, Fuel, vol. 125, pp. 1-14, 2014. DOI: 10.1016/j.fuel.2014.02.004

Siebers, D.L., Liquid-Phase Fuel Penetration in Diesel Sprays, SAE Technical Paper 980809, 1998. DOI: 10.4271/980809.

Wang, X., Huang, Z., Zhang, W., Abiola, O., and Nishida, K., Effects of ultra-high injection pressure and micro-hole nozzle on flame structure and soot formation of impinging diesel spray, Applied Energy, vol. 88, no. 5, pp. 1620-1628, 2011. DOI: $10.1016 /$ j.apenergy.2010.11.035.

Xu, Q., Xu, M., Hung, D., Wu, S., Dong, X., Ochiai, H., Zhao, Z., Wang, C., and Jin, K., Diesel Spray Characterization at Ultra-High Injection Pressure of DENSO 250 MPa Common Rail Fuel Injection System, SAE Technical Paper 2017-01-0821, 2017. DOI: $10.4271 / 2017-01-0821$.

Zhou, L.Y., Dong, S.F., Cui, H.F., Wu, X.W., Xue, F.Y., and Luo, F.Q., Measurements and analyses on the transient discharge coefficient of each nozzle hole of multi-hole diesel injector, Sensors and Actuators, A: Physical, vol. 244, pp. 198-205, 2016. DOI: $10.1016 / \mathrm{j}$. sna.2016.04.017. 